\title{
Economic importance of forestry-related sectors in the provincial and northwestern regional economy of Alberta
}

\author{
by Janaki R.R. Alavalapati ${ }^{1}$ and Wiktor L. Adamowicz ${ }^{2}$
}

This study examines the importance of forestry-related sectors relative to other resource sectors in the North West Region (NWR) of Alberta and the Alberta economy as a whole. A supply-side input-output analysis is conducted to achieve this task. The results indicate that the logging sector has the greatest potential among all resource sectors in generating output in Alberta for every additional unit of capital input. In the NWR, the pulp and paper sector is shown to be the key sector in generating output when compared to the other resource sectors. However, both logging and pulp and paper sectors are only next to the agricultural sector in generating employment for each unit of capital input. Results show that the energy sector has the least potential in generating output and employment both in the province and region.

\section{Introduction}

Many researchers have investigated the importance of the forestry sector at a provincial or national level. For example, Jacques (1988) analyzed the importance of forestry activities in Canada while Steel et al. (1988) investigated the role of the forestry sector in the Saskatchewan economy. Horne et al. (1991) assessed the impacts of a $10 \%$ reduction in forest-related supplies on employment and GDP in British Columbia. Siemens and Kulshreshtha (1995) assessed economic impacts of forest recreation-related activities on the Prince Albert Model Forest regional and the Saskatchewan economy. Ernst and Young (1994) described the absolute importance of the Alberta forest sector to the provincial economy. In this study, we investigate the relative importance of the forestry sector to the economy of Alberta and the North Western Region ${ }^{3}$ (NWR) of Alberta. Similar to the previous studies, we use inputoutput models to achieve the task. However, unlike previous studies, we focus on supply-side input-output analysis in determining the relative importance of the forestry sector for regional and provincial economies. If primary inputs are scarce and limited in supply, supply-side input-output analysis provides a convenient framework to determine the rela-

\footnotetext{
${ }^{1}$ Assistant Professor, School of Forest Resources and Conservation, University of Florida, Gainesville, FL, USA.

${ }^{2}$ Professor, Department of Rural Economy, University of Alberta, Edmonton, $\mathrm{AB}$.

${ }^{3}$ For the purpose of this study, NWR of Alberta includes ID 17, ID 21, ID 22, ID 23, and the town of Peace River.
}

Cette etude examine l'importance des secteurs relies a la foresterie par rapport aux autres secteurs se rapportant aux ressources dans la region du nord-ouest de l'Alberta et par rapport a l'economie de l'Alberta dans son ensemble. Une analyse des intrants et des extrants au niveau de l'approvisionnement a ete entreprise a cette fin. Les resultats indiquent que le secteur de l'exploitation forestiere a le plus fort potentiel entre toutes les autres ressources naturelles de generation d'extrants en Alberta pour chaque unite additionnelle de capitaux investis. Dans la region du nordouest, le secteur des pates et papiers s'illustre comme le secteurcle de la production d'extrants lorsqu'on le compare aux autres secteurs de ressources naturelles. Toutefois, l'exploitation forestiere et les pates et papier suivent tous deux l'agriculture en terme de creation d'emploi pour chaque unite de capital investi. Les resultats indiquent que le secteur de l'energie a le moins de potentiel de creation d'extrants et d'emploi au niveau de la province et de la region. tive importance of sectors in the economy (see Schallau and Maki 1983 for details).

In 1990, the Alberta forestry sector accounted for approximately $2.4 \%$ of the provincial economy and $1.4 \%$ of the provincial employment. On the other hand, the corresponding figures for the energy sector ${ }^{4}$ are $18 \%$ and $5.6 \%$. Relatively speaking, this suggests that the energy sector is more important than the forest sector in the economy of the province. However, economywide impacts of expansion in these sectors may tell a different story. For example, an additional use of scarce inputs (such as capital or labor) in the forestry sector may cause greater economic impacts than will use in the energy sector. ${ }^{5}$ Therefore, it is important for public agencies to have infor-

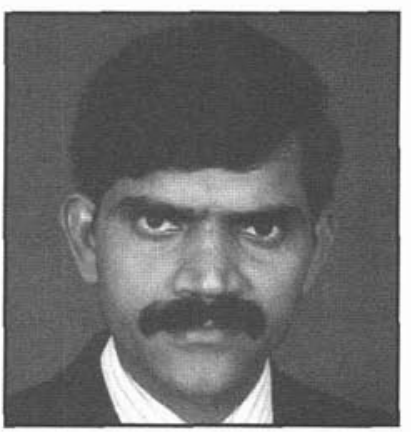

Janaki R.R. Alavalapati

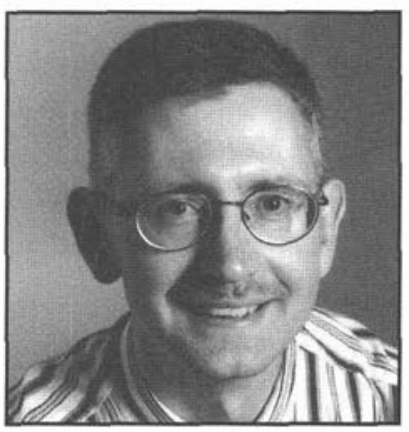

Wiktor L. Adamowicz

${ }^{4}$ The energy sector includes mining and oil and gas sectors.

${ }^{5}$ Schallau and Maki (1983) have noted that the greater the proportion of gross output disbursed to interindustry purchasers compared to final demand, the larger the impact of an additional unit of primary input. 
mation on each sector about their potentiality of generating output and employment in the economy for every additional unit of scarce input.

Input-output models provide a convenient framework to identify the impact of changes in a particular sector on the overall economy. In this analysis, production in a particular sector is assumed to have two kinds of impacts on other sectors in the economy. ${ }^{6}$ One effect results when final demands for outputs are modeled as exogenous variables. In this demandside input-output model, if sector $\mathrm{j}$ increases its output, there will be increased demand on other sectors whose products are used as inputs in the production of $\mathrm{j}$. This type of interconnection is termed "backward linkage." The total value of production in all sectors of the economy that is necessary to satisfy a dollar worth of final demand for sector j's output is called the "output multiplier" for sector $\mathrm{j}$.

The other impact in which we are interested results when factor supplies are viewed as exogenous variables. This supply-side input-output analysis assumes that increased output in sector $\mathrm{j}$ means there will be increased supplies from sector $\mathrm{j}$ for the sectors which use good $\mathrm{j}$ in their production. In other words, if the output of sector $\mathrm{j}$ is doubled, then the sales from $\mathrm{j}$ to each of the sectors that purchase from $\mathrm{j}$ will also be doubled. This kind of linkage of a particular sector to other sectors of the economy is called "forward linkage." This analysis measures the sensitivity of aggregate outputs to changes in the availability of primary inputs. The total increase in economy-wide production that results from an additional use of input in sector $\mathrm{j}$ is called the "input multiplier" of sector $\mathrm{j}$.

Both demand-side and supply-side input-output approaches can be used to identify leading sectors in any economy. In this study we conduct a supply-side analysis to identify the relative importance of the forest sector in the economy of Alberta and the NWR. Specifically, we note that if the forward linkage or input multiplier of sector $\mathrm{j}$ is larger than sector $\mathrm{i}$, it implies that it is more beneficial to invest an additional dollar in sector $\mathrm{j}$ than in $\mathrm{i}$. In other words, we address the question "where would an additional primary input (say a dollar of additional capital) be most beneficial in terms of potential growth in overall output?' In particular, we estimate economy-wide changes in output and employment in response to a $\$ 1000$ increase in the use of capital input in the agriculture, logging, wood products, pulp and paper, and energy sector.

The paper is organized as follows. The basic features of the supply-side input-output model are given in the next section. The details of updating the Alberta Input-Output Table (AIOT) from 1990 to 1995 and developing the North Western Region input-output table (RIOT) are discussed in the third section. Results of the supply-side analysis are presented and discussed in the fourth section. The final section concludes with a summary and discussion of the limitations of the study.

\section{The supply-side input-output model and its use in impact assessment}

Following Miller and Blair (1985), assume that we have the following data: a matrix of transactions between purchasing sectors and producing sectors, Z; a matrix of sales to final demand

\footnotetext{
${ }^{6}$ The following discussion is based on Miller and Blair (1985).
}

\begin{tabular}{lccc}
\hline \multicolumn{3}{c}{ Table 1. A standard input-output transaction table } \\
\hline & Purchasing sectors & Final demand & Total \\
Producing sectors & $\mathrm{Z}$ & $\mathrm{Y}$ & $\mathrm{X}$ \\
Primary inputs & $\mathrm{W}$ & & \\
Total & $\mathrm{X}^{\prime}$ & & \\
\hline
\end{tabular}

categories, Y; and a matrix of payments to primary factors from purchasing sectors, W, illustrated in Table 1 . The total gross outputs, $\mathrm{X}$ and $\mathrm{X}^{\prime}$, respectively are found as row sums of $\mathrm{Z}$ and $\mathrm{Y}$ and as column sums of $\mathrm{Z}$ and $\mathrm{W}$.

The first step in supply-side input-output analysis involves the calculation of the direct output coefficients.

$$
a_{i j}=\frac{z_{i j}}{X_{i}}
$$

Here, each $\mathrm{a}_{\mathrm{ij}}$, is interpreted as the amount of commodity i sold to sector $\mathrm{j}$ for every unit of output of sector $\mathrm{i}$. It is important to note that $\mathrm{Zi}$ row is divided by $\mathrm{X}_{\mathrm{i}}$. In matrix notation, we have

$$
A=\left(X^{d}\right)^{-1} Z \text { i.e., } \quad Z=X^{d} A
$$

Where $\mathrm{X}^{\mathrm{d}}$ is a square matrix with elements of $\mathrm{X}$ on the diagonals and zeros elsewhere. Note that $X^{\prime}=i^{\prime} Z+W$, where $i^{\prime}$ is a unit vector. Using equation (2), $\mathrm{X}^{\prime}$ can be written as

$$
X^{\prime}=i^{\prime}\left(X^{d}\right) A+W
$$

Rearranging equation (3) yields

$$
\begin{gathered}
X^{\prime}(I-A)=W \\
X^{\prime}=W(I-A)^{-1}
\end{gathered}
$$

For any exogenous changes in $\mathrm{W}$, equation (5) determines the changes in $\mathrm{X}^{\prime}$. In other words, we can find $\mathrm{X} \Delta^{\prime}$ from

$$
\Delta \mathrm{X}^{\prime}=\Delta W(I-A)^{-1}
$$

In any regional or national economy, the demand for commodities is met by domestic production, imports, inventory withdrawals, and government production of goods and services. Equation (6) does not account for imports, inventory withdrawals, and government production of goods and services. To the extent that these sources share the supply of a commodity, the impact of an increase in the final demand on local industries will be reduced. By incorporating imports, inventory withdrawals, and government production of goods and services, equation (6) can be written as

$$
\Delta X^{\prime}=\Delta W(I-(I-\mu-\alpha-\beta) A)^{-1}
$$

Where $\mu, \alpha$, and $\beta$, respectively, are fixed share coefficients of imports, inventory withdrawals, and government production of goods and services in the total demand. ${ }^{7}$

The values of $\Delta X^{\prime}$ can be interpreted as the direct and indirect amounts by which the outputs of producing sectors

${ }^{7}$ See Alberta Treasury (1974) for details of calculating coefficients of imports, inventory withdrawals, and government production of goods and services. 
would be changed for an exogenous change in primary inputs. For example, the sum of the $\mathrm{f}_{\mathrm{i}}$. st row elements in (I- $(\mathrm{I}-\mu-\alpha-$ $\beta) A)^{-1}$ represents the economy-- ide increase in the output, for a unit change in the availability of primary inputs in sector 1. Alternatively, it can be described as a direct and indirect or Type I "input multiplier" for sector 1. It should be noted that changes in output may generate incomes which may, in turn, stimulate additional demand for commodities. The values of $\Delta \mathrm{X}^{\prime}$ calculated by incorporating the outputs required to meet a given final demand and the outputs required to meet the change in final demand which is induced by changes in income are called direct, indirect, and induced impacts or Type II input multipliers (Alberta Treasury 1974). A comparison of input multipliers for each sector provides an indication of where an additional primary input would be most beneficial in terms of overall growth in the economy.

The changes in economy-wide output due to a change in the availability of primary inputs may cause changes in sectoral employment. Those changes can be calculated as follows. Let $\mathrm{L}_{\mathrm{j}}$ be the number of people to be employed in order to produce one unit of output in sector $\mathrm{X}_{\mathrm{j}} . \mathrm{L}_{\mathrm{j}}$ can be calculated as

$$
L_{j}=\frac{T L_{j}}{X_{j}}
$$

where TL is the total number of people employed in sector $\mathrm{j}$. By defining $\mathrm{L}$ as a column vector of employment coefficients which are calculated in equation (8), the changes in the economy-wide employment associated with the changes in sectoral output can be estimated by

$$
\Delta E=\Delta X_{j} L
$$

Where $\Delta \mathrm{X}$ is the change in sectoral output in response to an increase in the use of primary input in sector $j$. Therefore, $\Delta E$ can be interpreted as the direct and indirect change in employment for an additional use of primary input in sector $\mathrm{j}$.

\section{Updating Alberta I-O table and developing regional I-O table}

An input-output transaction table requires extensive information on both production and consumption of goods and services. Therefore, input-output tables are generally prepared at the provincial level once every five years. The input-output table which was available from Alberta Treasury for the province of Alberta was for the year 1990. With advancements in technology and changes in consumer preferences, it is assumed that growth in the producing sectors may not be uniform. Therefore, the available input-output table was updated from 1990 to 1995 following the procedure described below.

\section{Updating Alberta input-output table from 1990 to 1995}

Data on Alberta provincial sectoral output for 1995 were obtained from Statistics Canada. The Alberta sectoral output 1995 values which were expressed in 1984 prices were transformed to 1990 prices. Alberta sectoral output values for 1990 and 1995 which are reported in Table 2 suggest that the growth in sectoral output from 1990 to 1995 was approximately $\$ 20$ billion or $17 \%$ and growth was not uniform across sectors. For example, the growth in the logging sector was over
$136 \%$ from 1990 to 1995 while the growth was negative in the agriculture sector.

We followed McMenamin and Haring (1974) to update the provincial input-output table from 1990 to 1995 . This involves an iterative procedure which converges to a unique solution under equilibrium conditions (Siemens and Kulshreshtha 1995). Following McMenamin and Haring (1974), let

$\mathrm{X}=\left[\mathrm{x}_{\mathrm{ij}}\right]$ be an input-output table for 1990

$\mathrm{Y}=\left[\mathrm{y}_{\mathrm{i}}\right] \quad$ be a vector of sectoral gross outputs for year 1995

$\mathrm{Z}=\left[\mathrm{z}_{\mathrm{j}}\right] \quad$ be a vector of sectoral gross outlays for year 1995

$\mathrm{X}_{\mathrm{t}}=\left[\mathrm{x}_{\mathrm{t}, \mathrm{ij}}\right]$ be the regional input-output table after $\mathrm{t} / 2$ iter-

$\mathrm{i}=1, \ldots \mathrm{m}$ ations

$\mathrm{j}=1, \ldots \mathrm{n} \quad$ be the number of columns including the final demand sectors

The iterative process begins by constraining the row sums of the gross flows (sales) in $\mathrm{X}$ to the corresponding total gross output values:

$$
x_{1, i j}=\left(y_{i} / \sum_{k=1}^{n} x_{i k}\right)\left(x_{i j}\right)
$$

The column sums of these row-constrained gross flows (purchases) are then constrained to the total gross outlay values:

$$
x_{2, i j}=\left(z_{j} / \sum_{k=1}^{m} x_{1, k j}\right)\left(x_{1, i j}\right)
$$

These column-constrained gross flows are again constrained to the total gross output values. The process is continued until the vectors of row and column totals for the estimated matrix have converged to within of the total gross output and total gross outlay vectors:

$$
\begin{gathered}
y_{i}-\sum_{j=1}^{n} x_{t, i j}<\varepsilon \quad(i=1, \ldots, m) \\
z_{j}-\sum_{j=1}^{m} x_{t, i j}<\varepsilon \quad(i=1, \ldots, n)
\end{gathered}
$$

The matrix thus obtained, $\mathrm{X}_{\text {, }}$, is the estimated input-output table for 1995 . The value after the third iteration was less than $0.05 \%$. Therefore, data after the third iteration were considered as the Alberta input-output table 1995 (AIO95).

\section{Regionalization of the AIO95}

The relative magnitudes of the producing sectors may vary from the province to the NWR of Alberta. Employment figures by sector for the province and the NWR reported in Table 3 support the evidence of the difference in the composition of the economy. For example, the logging sector accounts for $0.43 \%$ and $2.56 \%$ employment respectively in the province and the NWR. The energy sector contributes $5.67 \%$ and $21.53 \%$ of employment respectively in the province and the NWR. Therefore, we developed the NWR input-output table 1995 (RIO95) using data from the AIO95. In creating the RIO95 
Table 2. Alberta sectoral output for 1990 and 1995 (Values are in \$millions)

\begin{tabular}{|c|c|c|c|}
\hline Sector & Output in 1995 & Output in 1990 & $\%$ change \\
\hline 1. Agriculture & 4858.3 & 4984.0 & -2.52 \\
\hline 2. Logging & 740.6 & 313.5 & 136.22 \\
\hline 3. Energy & 28154.6 & 21701.0 & 29.74 \\
\hline 4. Wood products & 1471.4 & 1056.6 & 39.26 \\
\hline 5. Pulp and paper & 2030.7 & 474.8 & 37.69 \\
\hline 6. Manufacturing & 22440.4 & 18011.4 & 24.59 \\
\hline 7. Construction & 13919.2 & 13407.5 & 3.82 \\
\hline 8. Transportation & 7089.6 & 5607.7 & 26.43 \\
\hline 9. Communication & 2569.6 & 2249.1 & 14.25 \\
\hline 10. Other utilities & 2959.8 & 2418.7 & 22.37 \\
\hline 11. Wholesale trade & 5185.8 & 4663.5 & 11.20 \\
\hline 12. Retail trade & 6113.8 & 5589.4 & 9.38 \\
\hline 13. Financial services & 19006.7 & 16898.9 & 12.47 \\
\hline 14. Business services & 22415.0 & 20136.0 & 11.32 \\
\hline Total & 138955.7 & 118512.6 & 17.25 \\
\hline
\end{tabular}

Table 3. Sector-wise employment in Alberta and NWR (As per 1991 census)

\begin{tabular}{|c|c|c|c|c|}
\hline Sector & $\begin{array}{c}\text { AB } \\
\text { Employment }\end{array}$ & $\begin{array}{c}\% \text { in total } \\
\text { employment }\end{array}$ & $\begin{array}{c}\text { NWR } \\
\text { employment }\end{array}$ & $\begin{array}{c}\% \text { in total } \\
\text { employment }\end{array}$ \\
\hline 1. Agriculture & 94700 & 6.74 & 3150 & 8.49 \\
\hline 2. Logging & 6045 & 0.43 & 950 & 2.56 \\
\hline 3. Energy & 79695 & 5.67 & 7985 & 21.53 \\
\hline 4. Wood products & 6063 & 0.43 & 387 & 1.04 \\
\hline 5. Pulp and paper & 8368 & 0.60 & 465 & 1.25 \\
\hline 6. Manufacturing & 92472 & 6.58 & 697 & 1.88 \\
\hline 7. Construction & 102095 & 7.27 & 2805 & 7.56 \\
\hline 8. Transportation & 65150 & 4.64 & 1460 & 3.94 \\
\hline 9. Communication & 35145 & 2.50 & 655 & 1.77 \\
\hline 10. Other utilities & 11000 & 0.78 & 70 & 0.19 \\
\hline 11. Wholesale trade & 64565 & 4.60 & 925 & 2.49 \\
\hline 12. Retail trade & 172700 & 12.29 & 3755 & 10.12 \\
\hline 13. Financial services & 70635 & 5.03 & 915 & 2.47 \\
\hline 14. Business services & 596195 & 42.44 & 12875 & 34.71 \\
\hline Total & 1404829 & 100.00 & 37095 & 100.00 \\
\hline
\end{tabular}

table, the location quotient method, a non-survey procedure, was followed.

The location quotient is a number comparing the relative performance of an industry in a region to its importance in the province or nation or some other base economy (Schaffer and Chu 1969). Following Schaffer and Chu (1969) it is defined for sector $i$ as:

$$
L Q_{i}=\frac{e_{i} / e}{E_{i} / E}
$$

where $\mathrm{e}_{\mathrm{i}}$ represents regional employment in sector $\mathrm{i}$, e total regional employment, $\mathrm{E}_{\mathrm{i}}$ the provincial employment in sector $\mathrm{i}$, and $E$ the total provincial employment. A location quotient equal to or greater than one means that the region is self-sufficient in the sector in question. On the other hand a location quotient less than one implies that the region imports some of its needs of output $i$ from the rest of the province.

If $L Q_{i} \geq 1$, we set $a_{i j}=A_{i j}$, where $a_{i j}$ is the NWR technical coefficient and $A_{i j}$ is the provincial technical coefficient. If $L_{i}$ $\leq 1$, local production is assumed to be inadequate to supply local needs and thus imports are necessary. Then the regional coefficients are computed as $\mathrm{a}_{\mathrm{ij}}=\mathrm{LQ}_{\mathrm{i}} \mathrm{A}_{\mathrm{ij},}$. The magnitudes of exports and imports are estimated by balancing supply and demand (see Schaffer and Chu 1969 for more details). It should be noted that there is an asymmetry in the LQ approach.
It leaves the national coefficients either unchanged or makes them smaller but will never increase their value. Therefore, this procedure is often called reducing the national coefficients table (Miller and Blair 1985).

\section{Economic impacts of changes in primary inputs in select- ed resource sectors}

The transaction tables developed for the province and the NWR are used to estimate the economy-wide output impacts of an increase in capital use by $\$ 1000$ in agriculture, logging, wood products, pulp and paper, and the energy sectors. Figure 1 shows the direct and indirect input multiplier (Type I multiplier) values of each resource sector at the NWR and the provincial level. The results show that the logging sector has the highest multiplier (2.4497) in the province while the pulp and paper sector has the highest multiplier (1.9268) in the NWR. This implies that additional investment in the logging sector would be more beneficial at the provincial level while additional investments in the pulp and paper sector would be more profitable in the NWR. On the other hand the wood products and energy sectors have the lowest multiplier values (1.3855 and 1.118 , respectively) in the province and the NWR. It should be noted that supply-side analysis assumes that if the output of sector $\mathrm{j}$ is doubled, then the sales from $\mathrm{j}$ to each of the sectors that purchase from $\mathrm{j}$ will also be doubled. According to this assumption, if a significant portion of output from a par- 


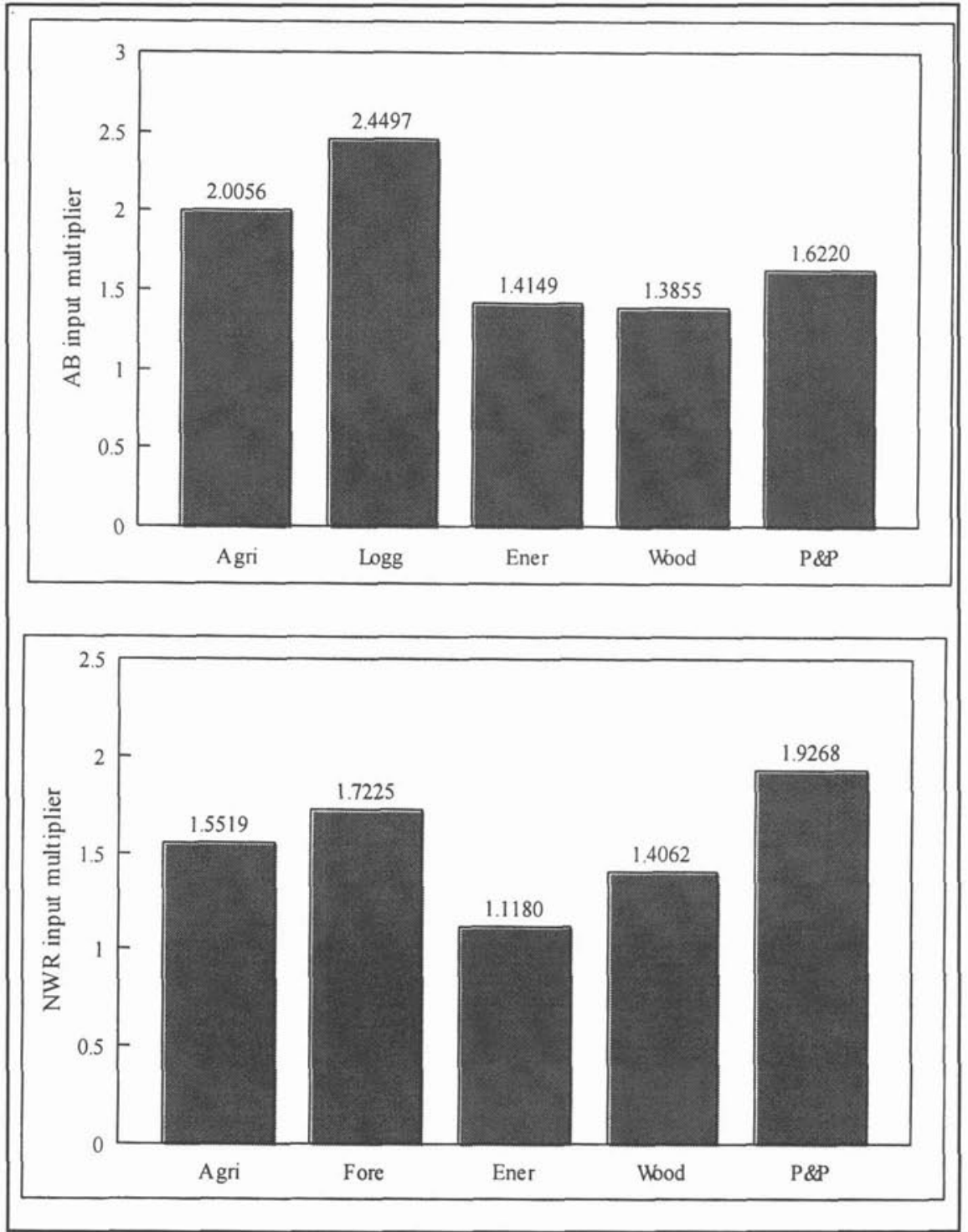

Fig. 1. Direct and indirect input multipliers of an additional use of $\$ 1000$ primary input in each resource sector of NWR and Alberta. ticular sector is exported, then one can expect that sector will have a smaller forward linkage in the domestic market. By selling larger quantities of output on the international market, the energy sector may have smaller forward linkages in the domestic market. On the contrary, large quantities of logs are used domestically to produce lumber and/or pulp. Therefore, the forward linkages of the logging sector are shown to be larger than those of the energy sector. Although large quantities of pulp are exported, printing and publishing activity forms a significant component in the pulp and paperrelated sector. This may be one reason why this sector has the largest multiplier values of those in the energy and wood product sectors.

Figure 2 reports direct, indirect, and induced input multiplier (Type II multiplier) values for the NW region and the province. It should be noted that Type II multiplier values are greater when compared to corresponding values of Type I multipliers. This result is not surprising because the effect of changes in income associated with the changes in the output on the demand for commodities is incorporated in calculating Type II multipliers.
Figure 3 shows the effect of an additional use of $\$ 1000$ of capital input in each resource sector on employment in the NWR and the province. The results indicate that agricultural sector investment is shown to generate the largest number of jobs of all the resource sectors both at the provincial and regional level. Investment in the energy sector is shown to generate the lowest number of jobs in both economies. Logging and pulp and paper sectors rank second, respectively, in the province and the region in generating employment. Figure 4 shows employment changes when the effect of changes in income associated with output changes on demand for commodities is incorporated in calculation. Again these values are larger when compared to those reported in figure 3 where personal expenditure was assumed exogenous.

\section{Conclusions and limitations of the study}

Public resource policy makers are often faced with questions regarding the economy-wide impact of additional use of scarce primary inputs (labor, capital, or land). Conventional demand-side input-output analysis cannot provide answers to 


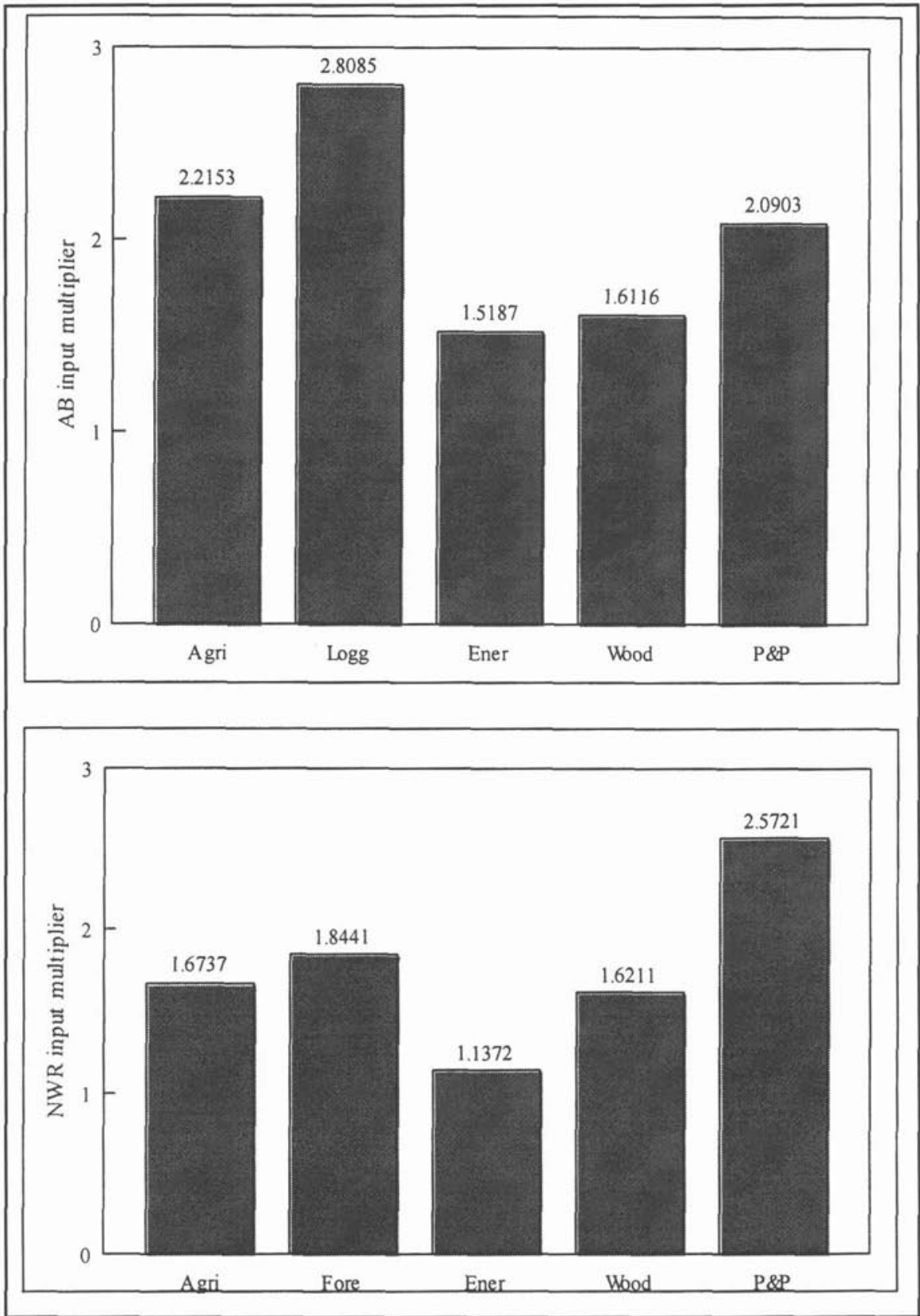

Fig. 2. Direct, indirect and induced input multipliers of an additional use of $\$ 1000$ primary input in each resource sector of NWR and Alberta. this type of question. A supply-side input-output model, however, provides a convenient framework to address these issues. In this study, we conducted a supply-side analysis to identify the relative importance of forest-related sectors in terms of generating output and employment in Alberta and the NWR. Assuming that the growth in sectors of the economy may not be uniform, we have updated the Alberta input-output table from 1990 to 1995 . Since input-output data for the NWR do not exist, we constructed the regional input-output table following the location quotient approach.

The results indicate that the logging- and pulp and paperrelated sectors have the greatest potential in generating output, respectively, at the provincial and the regional level. However, these are only second to the agricultural sector in generating employment for an additional investment both at the provincial and the regional level. On the other hand the energy sector, the biggest in terms of total output and employment, is shown to have the least potential in generating output and employment per dollar invested.

Several limitations of the study should be noted. The first one deals with the assumptions made in supply-side analysis. It is assumed that output distribution patterns are stable in an economic system. This implies that if the output of sector $i$ is doubled, then one might expect that sales from i to each of the sectors that purchase from i will also be doubled (Miller and Blair 1985). This assumption may not hold in some cases. For example, if the increased output in the pulp and paper sector is all exported, then multipliers calculated under the above assumptions may be biased. Second, the assumption of fixed coefficient technology does not allow industries to circumvent a short- 


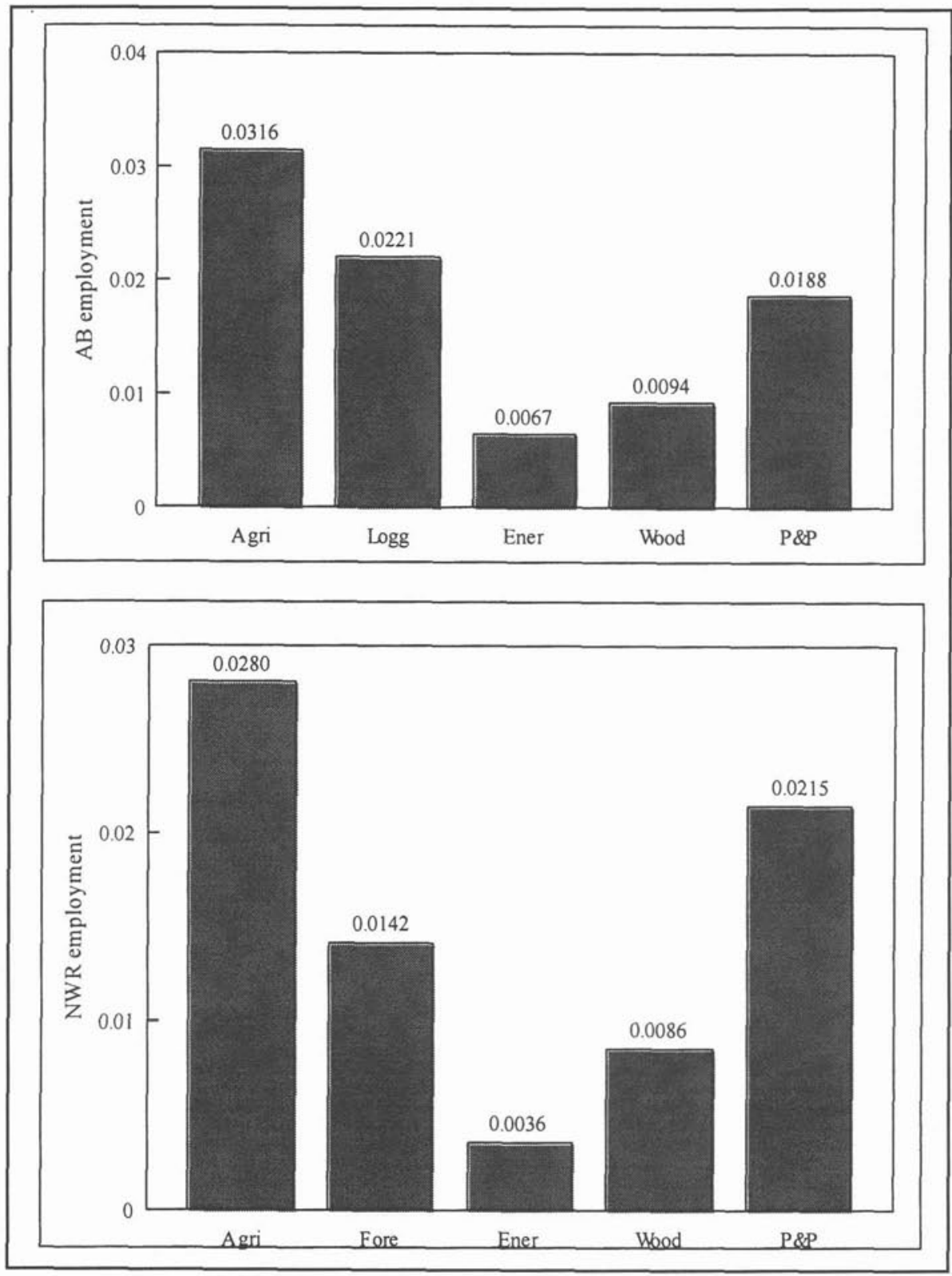

Fig. 4. Direct, indirect, and induced employment effects of an additional use of $\$ 1000$ primary input in each resource sector of NWR and Alberta. account for indirect interaction between industries (Parmenter 1982). It is possible that some sectors may not have direct links with other industries in terms of inter-industry flows of commodities. However, these sectors may still be interdependent in the sense that they have to compete for the economy's pool of primary factors. CGE models also can explain final demand by variables within the model. Because of these attractive features, a computable general equilibrium model is being constructed as an extension of this research effort to more accurately investigate changes in the forest sector of Alberta. ${ }^{8}$

\section{Acknowledgments}

This research was supported by the Sustainable Forest Management Network of Centres of Excellence. We wish to thank an anonymous referee for comments on this paper.

${ }^{8}$ This is not to suggest that CGE models are without limitations. See Hazledine and MacDonald (1992) for a critique of CGE models.
The Florida Agricultural Experiment Station, Journal Series No. 06527.

\section{References}

Alberta Treasury. 1974. The input-output structure of the Alberta Economy 1974. Alberta Bureau of Statistics, Edmonton, AB

Ernst and Young. 1994. A study of the economic importance of the forest sector in Alberta. Report \# 8034-110, Canadian Forest Service, Natural Resources Canada, Edmonton, AB.

Hazledine, T. and T. D. MacDonald 1992. A critique of computable general equilibrium for trade policy analysis. A paper presented at the International Agricultural Trade Research Consortium, December 12, New Orleans, LA.

Horne, G., N. Paul, and D. Riley. 1991. The provincial economic impacts of a supply reduction in the British Columbia forest sector. In Forest Resource Commission Background Papers; Vol. 4. Planning and Statistics Division, Ministry of Finance and Corporate Relations. Victoria, BC. 32 pp.

Jacques, R. 1988. Impact of forestry activity on the economy of Canada 
and its provinces: An input- output analysis. Canadian Forest Service. Information Report E-X-39. Ottawa, ON.

McMenamin, D.G, and J.H. Haring. 1974. An appraisal of nonsurvey techniques for estimating regional input-output models. Journal of Regional Science 14(2): 191-205.

Miller, R.E. and P.D. Blair. 1985. Input-output analysis: Foundations and extensions. Prentice-Hall, Inc., Englewood Cliffs, New Jersey.

O'Connor, R. and E. W. Henry. 1975. Input-output analysis and its applications. Charles Griffin and Company Ltd., London.

Parmenter, B.R. 1982. Inter-industry analysis: The ORANI model of Australia's industrial structure. In L.R. Webb and R.H. Allen (eds.). Industrial economics - Australian studies. Chapter 5. pp 69-110. Allen and Unwin, Boston.
Schallau, A.H. and W. R. Maki. 1983. Interindustry model for analyzing the regional impacts of forest resource and related supply constraints. Forest Science, 29(2): 384-394.

Schaffer, W.A. and K. Chu. 1969. Nonsurvey techniques for constructing regional interindustry models. Regional Science Association 23: 83-101.

Siemens, J. K. and S. N. Kulshreshtha. 1995. An economic impact assessment model for the Prince Albert Model Forest region. A report submitted to The Prince Albert Model Forest Association, P.O. Box 2406, Prince Albert, Saskatoon.

Steele, T.W., D.M. Boylen, and A. Baumgartner 1988. Saskatchewan forest industry, 1985. Canadian Forest Service Information Report NOR-X-295. Edmonton, AB. 